\title{
Serum concentrations of IL-17A, IL-17B, IL-17E and IL-17F in patients with systemic sclerosis
}

\author{
Ewa Robak ${ }^{1}$, Zofia Gerlicz-Kowalczuk², Bozena Dziankowska-Bartkowiak ${ }^{1}$, Anna Wozniacka ${ }^{1}$, \\ Jaroslaw Bogaczewicz ${ }^{1}$
}

${ }^{1}$ Department of Dermatology and Venereology, Medical University of Lodz, Lodz, Poland ${ }^{2}$ Department of Psychodermatology, Medical University of Lodz, Lodz, Poland

Submitted: 23 March 2018

Accepted: 25 May 2018

Arch Med Sci 2019; 15 (3): 706-712

DOI: https://doi.org/10.5114/aoms.2019.84738

Copyright (c) 2019 Termedia \& Banach

\section{Abstract}

Introduction: Immune system activation, microvascular abnormalities and extracellular matrix deposition in tissues play roles in systemic sclerosis (SSc). Th17 cells producing interleukin (IL)-17 are involved in the pathogenesis of many autoimmune-mediated inflammatory diseases; however, the role of IL-17 in SSc remains unclear.

Material and methods: The concentrations of IL-17A, IL-17B, IL-17E, and IL-17F in the serum of patients with SSC and in the healthy control group were assessed with regard to type of the disease - whether limited (ISSc) or diffuse (dSSc) - and symptoms.

Results: No difference was found between patients with SSc and the control group as regards the serum concentration of IL-17A. However, IL-17B and IL-17E levels in patients with SSc, and its types diffuse and limited were higher $(p<0.001)$ compared to the control. The serum level of IL-17F was higher in SSC $(p<0.005)$ and ISSC $(p<0.05)$ compared to the control. Serum concentration of IL-17B was elevated in SSc patients with renal abnormalities $(p<0.05)$ compared to those without. Serum levels of IL-17B correlated with the levels of IL-17E in patients with SSC $(r=0.54, p<0.05)$.

Conclusions: Increased synthesis of IL-17B, IL-17E and IL-17F appears to play a role in the pathogenesis of SSc, in contrast to IL-17A. Higher levels of IL-17B and IL-17E are associated with the development of both ISSC and dSSc, whereas IL-17F is associated with ISSc only. Further studies are needed to elucidate their role in the pathogenesis of the disease.

Key words: systemic sclerosis, scleroderma, interleukin 17, fibrosis.

\section{Introduction}

Systemic sclerosis (SSc) is a chronic autoimmune disease with an etiology that is not yet completely understood. The disease affects the skin and internal organs. Two forms of SSc are distinguished: a limited form (ISSc), which affects the face, hands and feet, and a diffuse form (dSSc) with skin thickening affecting the trunk, face and extremities proximal to the elbows and knees. Besides the skin, the condition can also affect the internal organs. Three processes play cardinal roles in the pathogenesis of SSc: activation of the immune system, microvascular abnormalities, and an increase of extracellular matrix deposition in tissues [1]. Abnormal activation of $T$ and $B$ cells results in excessive production of antinuclear antibodies (ANA), which are detected in $90 \%$ of patients. Im-

\author{
Corresponding author: \\ Prof. Ewa Robak \\ Department \\ of Dermatology \\ and Venereology \\ Medical University \\ of Lodz \\ Plac J. Hallera $1 / 6$ \\ 90-647 Lodz, Poland \\ Phone: +48 426867981 \\ Fax: +48 426884565 \\ E-mail: ewarobak@onet.eu
}


munological and microvascular abnormalities are predominant at an early stage of disease, whereas inflammation and fibrosis are observed in later stages [1].

Th17 cells are a novel subset of CD4+ T helper cells that play a pivotal role in the pathogenesis of many autoimmune-mediated inflammatory diseases, including SSc. The number of IL-17-producing Th17 cells is significantly elevated in the peripheral blood, skin lesions and lung tissues of patients with SSc [2-4].

The IL-17 cytokine family is composed of six structurally related molecules: IL-17A, IL-17B, IL-17C, IL-17D, IL-17E (IL-25) and IL-17F [5]. IL-17A and IL$17 \mathrm{~F}$ are mainly produced by immune cells, especially the T helper cell lineage of Th2 and Th17 cells. The other IL-17 cytokine family members, IL-17B, IL-17C, IL-17D, and IL-17E, are mainly produced by a non-T cell source. Th17-derived IL-17 is known to contribute to fibroblast proliferation, collagen production and the recruitment of inflammatory cells to vascular endothelial cells [2-4].

The aim of the study was to determine the serum concentrations of IL-17A, IL-17B, IL-17E and IL-17F in patients with systemic sclerosis with regard to extent of skin sclerosis, type of the disease (whether limited or diffuse), and involvement of internal organs.

\section{Material and methods}

\section{Studied group}

The study included 45 patients with systemic sclerosis (SSc) who fulfilled the 1980 criteria of the American College of Rheumatology, and the 2013 ACR/EULAR SSc Classification Criteria for SSc [6, 7]. According to LeRoy's classification, 33 of the study group were suffering from limited systemic sclerosis (ISSc) and 12 from diffuse systemic sclerosis (dSSc) [8]. The control group consisted of 21 healthy subjects with no systemic diseases, matched according to age (17-70 years) and gender (19 women and two men). All participants gave their written informed consent, approved by the Ethical Committee of the Medical University of Lodz.

\section{Clinical assessment}

Medical histories were obtained and patients underwent a complete physical examination including ECG, echocardiography, chest radiography, high-resolution computed tomography, esophageal scintigraphy, blood tests and bone marrow biopsy if needed. Cardiovascular involvement was defined as abnormal cardiac rhythm or documented fibrosis of the myocardium. Pulmonary involvement was defined as the presence of a ground glass or honeycomb appearance, suggesting lung fibrosis. Esophageal changes were diagnosed on the basis of impaired transit in scintigraphy. Serum creatinine levels above $100 \mu \mathrm{mol} / \mathrm{l}$ or proteinuria defined as levels above $500 \mathrm{mg}$ for $24 \mathrm{~h}$ (after excluding other causes) or a documented renal crisis in the past indicated renal involvement. Hematological involvement was diagnosed in the case of leukopenia or anemia, after excluding other causes. The duration of the disease, the onset of Raynaud's phenomenon, ulcerations in fingertip pulp and previous or current treatment regimens were also considered.

\section{Measurement of cytokine concentrations}

Blood samples were taken between 7:00 and 9:00 a.m., allowed to clot at $4^{\circ} \mathrm{C}$ for $1 \mathrm{~h}$ and centrifuged at $2000 \mathrm{~g}$ for $10 \mathrm{~min}$. The obtained serum was divided into aliquots and stored at $-80^{\circ} \mathrm{C}$ until analysis. Clinical, laboratory and treatment data were collected when the blood samples were drawn. In our 45 patients, 22 (48.8\%) were treated with immunosuppressants (cyclophosphamide or methotrexate) and glucocorticosteroid in various combinations and different doses, once daily, in the morning. Blood was collected before taking the morning doses of drugs. Drugs, including corticosteroids and immunosuppressants, were stopped $24 \mathrm{~h}$ before blood collection.

Measurements of IL-17A, IL-17B, IL-17E and IL-F in serum samples were performed using ELISA sandwich kits (R\&D Systems Inc, Minneapolis, USA) following the manufacturer's instructions. Both standards and samples were evaluated in duplicate and the inter-assay variations were shown to be within the range given by the manufacturers. The lower detection limits for measured interleukins were as follows: IL-17A 0 pg/ml, IL-17 B 2.5 pg/ $\mathrm{ml}$, IL-17E $0 \mathrm{pg} / \mathrm{ml}, \mathrm{IL}-17 \mathrm{~F} 0 \mathrm{pg} / \mathrm{ml}$. According to the manufacturer's data, in the case of IL-17 there is $<0.5 \%$ cross-reactivity observed with available related molecules. Measurement of IL-17A was performed twice using two ELISA kits, because at the first measurement IL-17A level was close to zero concentration in both SSc patients and in the control group. During the second measurement the IL-17A level was also close to zero concentration.

\section{Statistical analysis}

All analyses were performed with Statistica, version 12 (StatSoft, Poland). The Shapiro-Wilk test did not confirm normal distribution of serum concentrations of IL-17. Therefore nonparametric tests were used such as the Mann-Whitney $U$ test to compare results of serum concentrations between two groups, and Spearman's rank correlation to measure statistical dependence between two concentrations, whereas graphic representa- 
tion of the correlation was displayed by scatterplot. Concentrations were represented as median with lower $\left(25^{\text {th }}\right)$ and upper $\left(75^{\text {th }}\right)$ quartile $\left(25^{\text {th }}\right.$ $75^{\text {th }}$ centile), and mean \pm standard deviation of the mean. The descriptive data regarding age, disease duration and duration of Raynaud's phenomenon were displayed as mean \pm standard deviation of the mean. In all calculations a $p$-value less than 0.05 was regarded as statistically significant.

\section{Results}

The patients' clinical characteristics are presented in Table I.

Serum concentrations of IL-17A, IL-17B, IL-17E and IL-17F in patients with systemic sclerosis (SSC), its types diffuse (dSSc) and limited (ISSc), and in the healthy control group are shown in Table II.

No difference was found in serum level of IL-17A between the patients with SSC and the control group. (Figure 1).
No difference with regard to IL-17A was revealed between patients either with diffuse or limited types of SSc and control subjects (data not shown).

The serum level of IL-17B was higher in patients with SSc $(p<0.001)$ compared to the control group. Serum levels of IL-17B were increased in both $\mathrm{dSSC}(p<0.001)$ and ISSC $(p<0.001)$ groups compared to the control group. No difference was revealed in IL-17B level between dSSC and ISSc groups.

The serum concentration of IL-17E was higher in patients with SSc $(p<0.001)$, dSSc $(p<0.001)$ and ISSc $(p<0.001)$ than in the control group, and no difference was revealed between $\mathrm{dSSc}$ and ISSc groups.

The serum level of IL-17F was higher in the SSC $(p<0.005)$ and ISSc $(p<0.05)$ group compared to the control group. No difference was revealed in IL-17F level between dSSc patients and the controls or between dSSc and ISSc groups.

Table I. Clinical characteristics of patients with systemic sclerosis (SSC), and its types - limited (ISSC) and diffuse (dSSc)

\begin{tabular}{|lccc|}
\hline Parameter & $\begin{array}{c}\text { SSc } \\
(n=45)\end{array}$ & $\begin{array}{c}\text { Limited SSc } \\
(n=33)\end{array}$ & $\begin{array}{c}\text { Diffuse SSc } \\
(n=12)\end{array}$ \\
\hline Sex (female/male) & $42 / 3$ & $31 / 2$ & $11 / 1$ \\
\hline Age [years] & $55.6 \pm 11.1$ & $55.8 \pm 11.8$ & $54.6 \pm 9.1$ \\
\hline Age at onset of disease [years] & $44.6 \pm 12.0$ & $43.9 \pm 13.2$ & $46.5 \pm 8.0$ \\
\hline Disease duration [years] & $9.6 \pm 6.2$ & $10.0 \pm 6.4$ & $8.0 \pm 5.7$ \\
\hline Duration of Raynaud's phenomenon [years] & $13.8 \pm 7.8$ & $15.3 \pm 7.9$ & $9.5 \pm 6.3$ \\
\hline Gastrointestinal manifestation & $27(60 \%)$ & $19(58 \%)$ & $8(67 \%)$ \\
\hline Cardiac involvement & $31(69 \%)$ & $21(64 \%)$ & $10(83 \%)$ \\
\hline Pulmonary fibrosis & $19(42 \%)$ & $13(39 \%)$ & $6(50 \%)$ \\
\hline Renal abnormalities & $7(16 \%)$ & $2(6 \%)$ & $5(42 \%)$ \\
\hline Hematological involvement & $11(24 \%)$ & $8(24 \%)$ & $3(25 \%)$ \\
\hline Arthralgia & $32(71 \%)$ & $23(70 \%)$ & $9(75 \%)$ \\
\hline
\end{tabular}

Results are shown as number and percent. Duration is represented in years as mean \pm standard deviation of the mean.

Table II. Serum concentrations of IL-17A, IL-17B, IL-17E and IL-17F in patients with systemic sclerosis (SSc), its types (limited and diffuse), and in the healthy control group

\begin{tabular}{|c|c|c|c|c|}
\hline Variable & $\begin{array}{l}\text { Systemic sclerosis } \\
(\mathrm{SSc})(n=45) \\
\text { Median }\left(25^{\text {th }}-75^{\text {th }}\right) \\
\text { Mean } \pm \text { SD }\end{array}$ & $\begin{array}{l}\text { Limited SSc }(n=33) \\
\text { Median }\left(25^{\text {th }}-75^{\text {th }}\right) \\
\text { Mean } \pm \text { SD }\end{array}$ & $\begin{array}{l}\text { Diffuse SSc }(n=12) \\
\text { Median }\left(25^{\text {th }}-75^{\text {th }}\right) \\
\text { Mean } \pm \text { SD }\end{array}$ & $\begin{array}{l}\text { Healthy control group } \\
\qquad(n=21) \\
\text { Median }\left(25^{\text {th }}-75^{\text {th }}\right) \\
\text { Mean } \pm \text { SD }\end{array}$ \\
\hline IL-17A [pg/ml] & $\begin{array}{c}0.0(0.0-0.0) \\
1.36 \pm 8.27\end{array}$ & $\begin{array}{c}0.0(0.0-0.0) \\
0.15 \pm 0.62\end{array}$ & $\begin{array}{c}0.0(0.0-0.0) \\
4.68 \pm 16.0\end{array}$ & $\begin{array}{c}0.0(0.0-0.0) \\
0.59 \pm 1.96\end{array}$ \\
\hline IL-17B [pg/ml] & $\begin{array}{c}45.8(15.6-87.1) \\
82.84 \pm 126.76\end{array}$ & $\begin{array}{c}29.9(15.2-78.4) \\
58.32 \pm 59.95\end{array}$ & $\begin{array}{c}60.6(32.7-204.1) \\
150.25 \pm 216.93\end{array}$ & $\begin{array}{c}0.0(0.0-1.7) \\
2.47 \pm 5.3\end{array}$ \\
\hline IL-17E [pg/ml] & $\begin{array}{c}5.5(2.0-9.3) \\
7.67 \pm 8.94\end{array}$ & $\begin{array}{c}4.7(2.0-7.9) \\
6.87 \pm 8.12\end{array}$ & $\begin{array}{c}6.9(2.2-12.95) \\
9.87 \pm 10.97\end{array}$ & $\begin{array}{c}0.2(0.0-1.1) \\
0.6 \pm 0.75\end{array}$ \\
\hline $\mathrm{IL}-17 \mathrm{~F}[\mathrm{pg} / \mathrm{ml}]$ & $\begin{array}{c}0.0(0.0-0.5) \\
0.4 \pm 1.24\end{array}$ & $\begin{array}{c}0.0(0.0-0.5) \\
0.49 \pm 1.42\end{array}$ & $\begin{array}{c}0.0(0.0-0.0) \\
0.18 \pm 0.47\end{array}$ & $\begin{array}{c}0.0(0.0-0.0) \\
0 \pm 0\end{array}$ \\
\hline
\end{tabular}

Results are displayed as median, lower $\left(25^{\text {th }}\right)$ and upper $\left(75^{\text {th }}\right)$ quartile, mean \pm standard deviation of the mean (SD). 
A

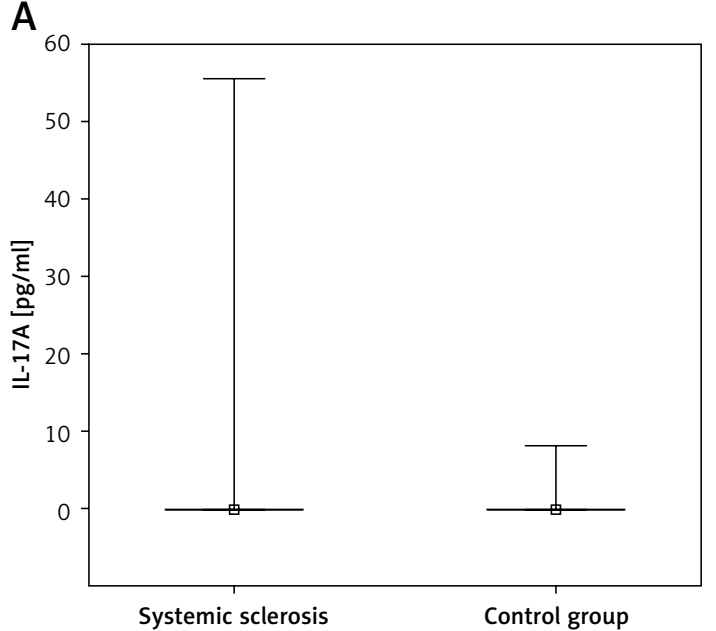

C

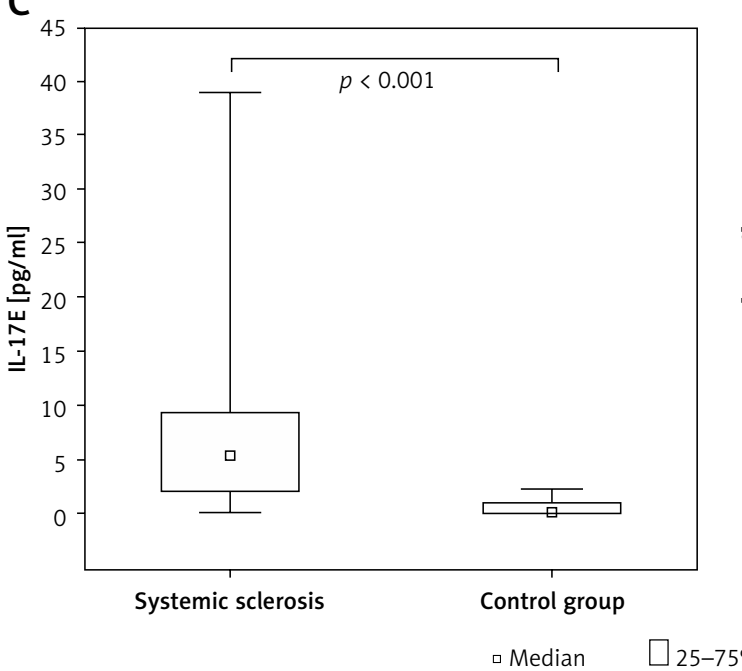

B

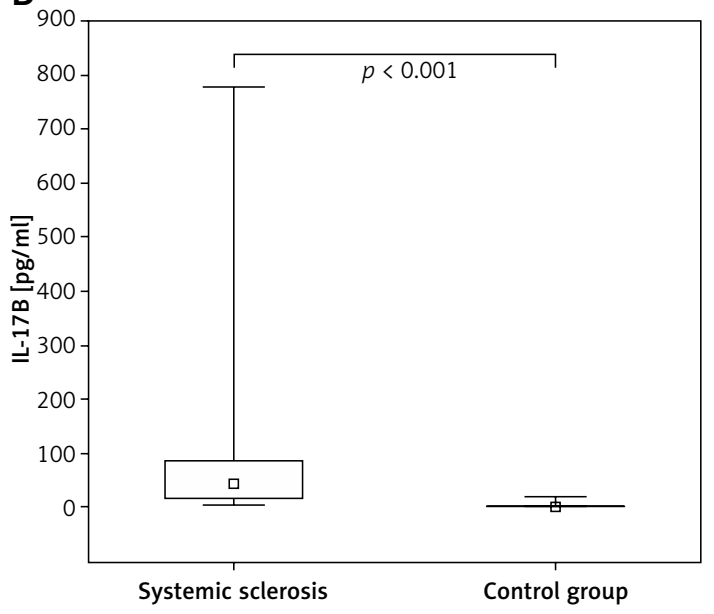

D

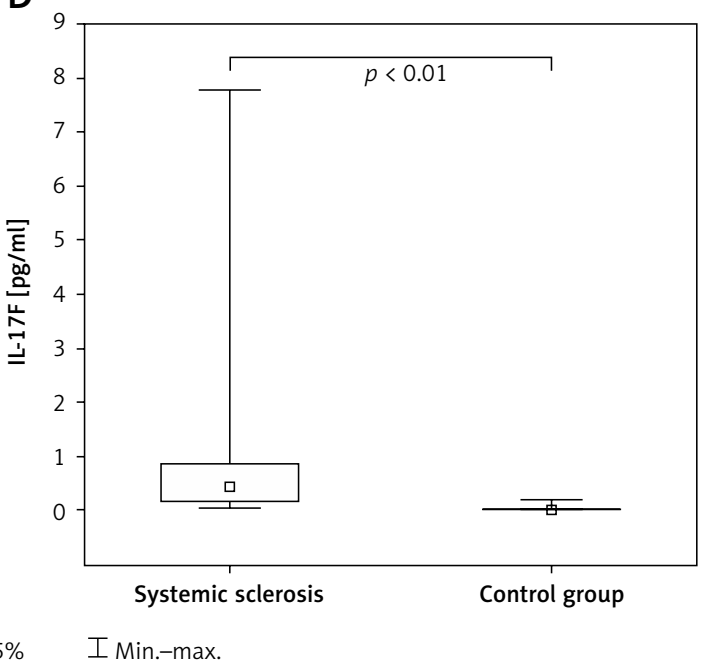

Figure 1. Comparison of serum concentrations of IL-17A (A), -17B (B), -17E (C) and -17F (D) in patients with systemic sclerosis and in the control group. In all calculations the Mann-Whitney $U$ test was used

As regards clinical manifestation of the disease and analysis of each organ involvement separately, no difference was found in serum concentration of IL-17A between SSc patients with gastrointestinal manifestation, cardiac involvement, pulmonary fibrosis, renal abnormalities, hematological involvement, arthralgia and those without (data not shown).

In contrast to IL-17A, the serum concentration of IL-17B was higher in SSc patients with renal abnormalities ( $n=7)$ compared to those without $(n=38)$ (respectively $64.7(45.8-267.8) \mathrm{pg} / \mathrm{ml}) \mathrm{vs}$. 31.1 (14.7--84.4) pg/ml, $p<0.05$ ) (Figure 2).

No difference was revealed in IL-17B level between SSc patients with involvement of other organs compared to those without (data not shown).

Serum concentrations of IL-17E and IL-17F did not differ in SSc patients with regard to gastrointestinal manifestation, cardiac involvement, pulmonary fibrosis, renal abnormalities, hematological involvement, or arthralgia compared to those without (data not shown).
Serum levels of IL-17B correlated with the levels of IL-17E in patients with SSC ( $r=0.54, p<$ 0.05) (Figure 3).

\section{Discussion}

The mean serum concentrations of IL-17B, IL-17E and IL-17F were found to be increased in patients with systemic sclerosis. Hence, it is reasonable to assume that cytokines of the IL-17 family play a role in its pathogenesis. IL-17A is released from Th17 lymphocytes and has well-characterized proinflammatory properties. In our studied group of patients with systemic sclerosis, the mean serum level of IL-17A was low, and was not found to differ from that of healthy individuals, and no relationship was observed between IL-17A levels and clinical manifestations of the disease. Since IL-17A concentrations were low, in order to draw convincing conclusions further studies using more sensitive detection systems are needed. IL-17A and IL-17F bind to the same receptors and mediate host defensive mechanisms against infec- 


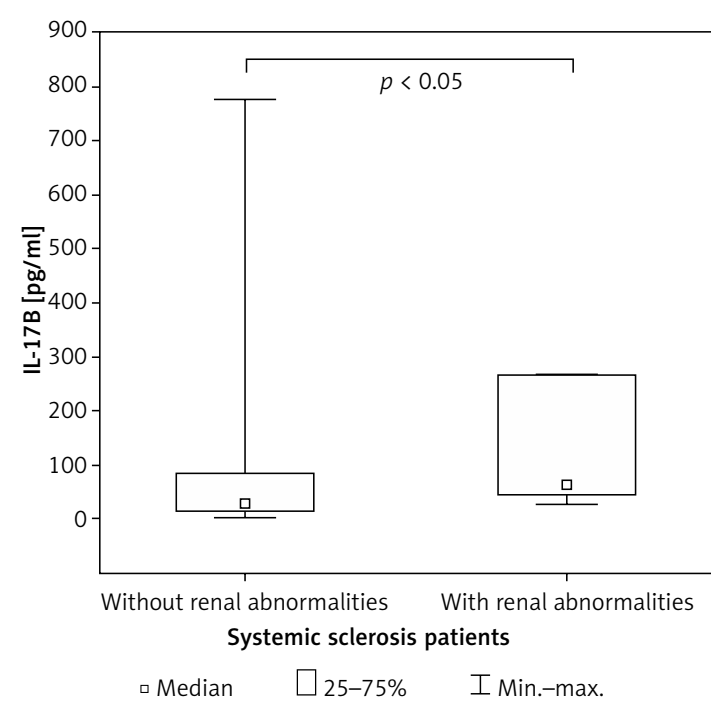

Figure 2. Increased serum concentration of IL-17B in systemic sclerosis patients with renal abnormalities. In statistical analysis the Mann-Whitney $U$ test was used

tions, in particular those caused by extracellular bacteria and fungi [9]. The literature regarding the role of IL-17A in systemic sclerosis is quite ambiguous: while some studies report an elevated level of IL-17A in systemic sclerosis, others note no such elevation in the early and late stages of the disease, and no difference was found between dSSc and ISSc [10-14]. It has been suggested that IL-17 level measurement is not sensitive enough to give a clear picture of the profile of Th17 lymphocytes in SSc. Chizzolini et al. stated that in patients with SSc serum levels of IL-17A are generally low and near the detection level of the assays, thus explaining the variability of the results regarding clinical characteristics of the study populations [15]. Some studies indicate that IL-17A plays a pivotal role in the early, inflammatory stage of the disease, characterized by the predominance of Th1 and Th17 cells. In contrast, in the late stage, Th2 cells are more relevant [4, 10-12].

There is also a possibility of the presence of antibodies directed against IL-17A, which are found in plasma of patients with rheumatoid arthritis. Such autoantibodies could potentially interfere with ELISA assay [16]. However, further studies are needed to determine whether they are present in serum of patients with SSc.

As the mean disease duration in the present study was 9.6 years, most patients were at the chronic stage of the disease. This fact may be responsible for the decreased concentration of IL-17A related to Th17 polarization in the early stage of SSc. However, in the final stage, Th17 may play a role in fibrosis. In animal models, using mice undergoing treatment with bleomycin, increased expression of IL-17A was responsible for fibrosis of the lungs and the skin [17]. This suggests that in

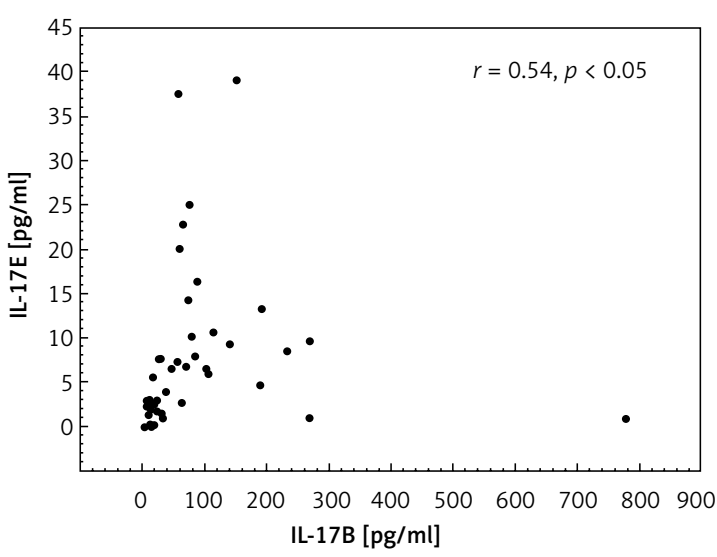

Figure 3. Correlation between serum levels of IL-17B and IL-17E in patients with SSc. In statistical analysis Spearman's rank correlation was used

humans IL-17A could play an analogous role, and dominate in the early stage of SSc, when immune and vascular disorders are more predominant than fibrosis [17]. Moreover, it was found that the blockage of IL-17A activity results in thinning of the skin in mice and promotes the resolution of pulmonary inflammation and fibrosis induced by bleomycin [18-20].

Since fibrosis progresses in SSc for years and is predominant in the late stage of the disease, the decreased concentration of IL-17A found in our patients and also reported by other authors may be related to a complex process in which vascular and immune disorders are more predominant than fibrosis. However, data regarding the role of IL-17A in fibrosis are more complex, including those that do not support a role for IL-17A as a pro-fibrotic cytokine in SSc. Nakashima et al. reported that the protein synthesis of $\alpha 1$ (I) collagen was significantly decreased by treatment with IL-17A in comparison with untreated cells in normal fibroblasts [21].

An important novel finding of the present study is that our results indicate elevated concentrations of IL-17B, IL-17E and IL-17F in SSc patients. The serum concentrations of IL-17B and IL-17E were also increased in both the dSSC and ISSc groups when compared to the healthy control group. At this point we need to underline the limitations of our study and the fact that we have not performed further testing of potential cross-reactivity between IL-17B and IL-17E, which is possible. According to data provided by the manufacturer, IL-17B prepared at the concentration of $50 \mathrm{ng} / \mathrm{ml}$ exhibited no cross-reactivity with IL-17E. In our study serum concentrations of IL-17B and IL-17E were detected at the level of picograms $/ \mathrm{ml}$. However, beyond the manufacturer considerations, such testing would provide more convincing evidence.

Little is known about the action of IL-17B; however, its expression has been reported in a wide 
range of tissues and cells, including chondrocytes, spinal cord neurons, the testis, stomach, small intestine, pancreas, prostate and ovary. The cytokine binds to IL-17RB, though with lower affinity than IL-17E, and stimulates the synthesis of TNF- $\alpha$ and IL-1 $\beta$ by the monocytic cell line $[22,23]$. In mice with collagen-induced arthritis, it was found to be highly expressed in the cartilage derived from the paws. The blockage of IL-17B using antibodies suppressed the progression of arthritis and bone destruction. It suggests the presence of a correlation between IL-17B and the progression of arthritis, and that IL-17B could be an important target for the treatment of inflammatory arthritis, as is the case for IL-17A [24]. In contrast to IL-17A and IL-17F, which are expressed in CD4+ $T$ cells, IL-17B is expressed exclusively in the inflammatory cartilage of mice [24]. IL-17B was found to induce the expression of IL-1 $\beta$, IL- 6 and $\mathrm{IL}-23$ in mouse macrophages and IL- $1 \beta$ in mouse fibroblasts [23]. However, the expression of IL-17B in humans remains poorly understood, and further studies on its functions are needed [25]. Our results indicate that the serum concentration of IL-17B was increased in patients with SSc, which suggests that it is involved in the pathogenesis of this disease. IL-17B was found to be particularly elevated in dSSc, which is in accordance with the wide distribution range of IL-17B. Regarding organ involvement, IL-17B concentration was increased in SSc patients with renal abnormalities, the location characterized by well-developed blood vessels. However, there were only 7 patients with renal abnormalities, which could be attributed to different causes. Because of the small number of patients, this group was not stratified. Therefore further studies on a larger group of patients with more specific renal abnormalities are necessary.

The serum concentration of IL-17E was also higher in patients with SSc than in healthy individuals, and was elevated in those with dSSC. IL-17E, also known as IL-25, is characterized by the lowest sequence homology (29\%) with IL-17A, and its activity is different from IL-17A. IL-17E is expressed by a variety of cells, such as CD4+ cells, CD8+ $\mathrm{T}$ cells, macrophages, dendritic cells, mast cells, eosinophils, epithelial and endothelial cells, and in a pathological setting it can potentiate allergic inflammation [23-30]. In contrast to IL-17A, IL-17E influences type 2 immunity and inhibits Th17-mediated inflammation [23, 27-31]. Increased numbers of IL-17E+ cells were found in the dermis of both morphea and systemic sclerosis. It seems that IL-17E may enhance fibrosis by favoring a Th2-like response via IL-4 and IL-13, which induce the synthesis of collagen by fibroblasts and induce activated macrophages. Macrophages can both stimulate and prevent fibrotic processes, although the underlying mechanisms remain partly elusive [32].
The observed correlation between the increased serum concentrations of IL-17E and IL-17B indicates a link between them. IL-17E and IL-17B share a common source, lymphocytes. Therefore, they may play a role in immune, allergic, inflammatory and anti-infective responses. Other sources of IL-17B and IL-17E are fibroblasts, epithelial and endothelial cells, which are involved in fibrosis, angiogenesis and the immune response. As these processes are involved in the pathogenesis of SSc, and fibrosis predominates with time, it may be helpful to monitor the level of the two cytokines in the course of SSc to assess the extent and staging of the disease.

In conclusion, increased synthesis of IL-17B, IL-17E and IL-17F appears to play a role in the pathogenesis of SSC, in contrast to IL-17A. Higher levels of IL-17B and IL-17E are associated with the development of both ISSc and dSSc, whereas IL-17F is associated with ISSc only. Further studies are needed to elucidate their role in the pathogenesis of the disease.

\section{Acknowledgments}

This work was supported by the Medical University of Lodz, Poland, Grant no. 503/1-15201/503-11-002.

\section{Conflict of interest}

The authors declare no conflict of interest.

\section{References}

1. Barsotti S, Stagnaro C, Della Rossa A. Systemic sclerosis: a critical digest of the recent literature. Clin Exp Rheumatol 2015; 33: 3-14.

2. Xing X, Yang J, Yang X, et al. IL-17A induces endothelial inflammation in systemic sclerosis via the ERK signaling pathway. PLoS One 2013; 8: e85032.

3. Rodríguez-Reyna TS, Furuzawa-Carballeda J, Cabiedes J, et al. Th17 peripheral cells are increased in diffuse cutaneous systemic sclerosis compared with limited illness: a cross-sectional study. Rheumatol Int 2012; 32: 2653-60.

4. Radstake TR, van Bon L, Broen J, et al. The pronounced Th17 profile in systemic sclerosis (SSc) together with intracellular expression of TGFbeta and IFNgamma distinguishes SSc phenotypes. PLoS One 2009; 4: e5903.

5. Kolls JK, Lindén A. Interleukin-17 family members and inflammation. Immunity 2004; 21: 467-76.

6. Subcommittee for Scleroderma Criteria of the American Rheumatism Association Diagnostic and Therapeutic Criteria Committee Preliminary criteria for the classification of systemic sclerosis (scleroderma) Arthritis Rheum 1980; 23: 581-90.

7. van den Hoogen F, Khanna D, Fransen J, et al. 2013 classification criteria for systemic sclerosis: an American College of Rheumatology/European League against Rheumatism collaborative initiative. Arthritis Rheum 2013; 65: 2737-47.

8. LeRoy E, Black C, Fleischmajer R, et al. Scleroderma (systemic sclerosis): classification, subsets and pathogenesis. J Rheumatol 1988; 15: 202-5. 
9. Murdaca G, Colombo BM, Puppo F. The role of Th17 lymphocytes in the autoimmune and chronic inflammatory diseases. Intern Emerg Med 2011; 6: 487-95.

10. Kurasawa K, Hirose K, Sano H, et al. Increased interleukin-17 production in patients with systemic sclerosis. Arthritis Rheum 2000; 43: 2455-63.

11. Murata M, Fujimoto M, Matsushita T, et al. Clinical association of serum interleukin-17 levels in systemic sclerosis: is systemic sclerosis a Th17 disease? J Dermatol Sci 2008; 50: 240-2.

12. Mathian A, Parizot C, Dorgham K, et al. Activated and resting regulatory $T$ cell exhaustion concurs with high levels of interleukin-22 expression in systemic sclerosis lesions. Ann Rheum Dis 2012; 71: 1227-34.

13. Dantas AT, Almeida AR, Sampaio MC, et al. Different profile of cytokine production in patients with systemic sclerosis and association with clinical manifestations. Immunol Lett 2018; 198: 12-6.

14. Rolla G, Fusaro E, Nicola S, et al. Th-17 cytokines and interstitial lung involvement in systemic sclerosis. J Breath Res 2016; 10: 046013

15. Chizzolini C, Dufour AM, Brembilla NC. Is there a role for IL-17 in the pathogenesis of systemic sclerosis? Immunol Lett 2018; 195: 61-7.

16. Ndongo-Thiam N, Clement A, Pin JJ, Razanajaona-Doll D, Miossec P. Negative association between autoantibodies against IL-17, IL-17/anti-IL-17 antibody immune complexes and destruction in rheumatoid arthritis. Ann Rheum Dis 2016; 757: 1420-2.

17. Wilson MS, Madala SK, Ramalingam TR, et al. Bleomycin and IL-1beta-mediated pulmonary fibrosis is IL-17A dependent. J Exp Med 2010; 207: 535-52.

18. Gasse P, Riteau N, Vacher R, et al. IL-1 and IL-23 mediate early IL-17A production in pulmonary inflammation leading to late fibrosis. PLoS One 2011; 6: e23185.

19. Mi S, Li Z, Yang HZ, et al. Blocking IL-17A promotes the resolution of pulmonary inflammation and fibrosis via TGF-beta1-dependent and -independent mechanisms. J Immunol 2011; 187: 3003-14.

20. Okamoto Y, Hasegawa M, Matsushita T, et al. Potentia roles of interleukin-17A in the development of skin fibrosis in mice. Arthritis Rheum 2012; 64: 3726-35.

21. Nakashima T, Jinnin M, Yamane K, et al. Impaired IL-17 signaling pathway contributes to the increased collagen expression in scleroderma fibroblasts. J Immunol 2012; 188: 3573-83.

22. Li H, Chen J, Huang $A$, et al. Cloning and characterization of IL-17B and IL-17C, two new members of the IL-17 cytokine family. Proc Natl Acad Sci USA 2000; 97: 773-8.

23. Iwakura Y, Ishigame $H$, Saijo S, Nakae S. Functional specialization of interleukin-17 family members. Immunity 2011; 34: 149-62.

24. Yamaguchi Y, Fujio K, Shoda H, et al. IL-17B and IL-17C are associated with TNF-alpha production and contribute to the exacerbation of inflammatory arthritis. J Immunol 2007; 179: 7128-36.

25. Cai S, Batra S, Langohr I, Iwakura Y, Jeyaseelan S. IFN-gamma induction by neutrophil-derived IL-17A homodimer augments pulmonary antibacterial defense. Mucosal Immunol 2016; 9: 718-29.

26. Suzukawa M, Morita $H$, Nambu A, et al. Epithelial cell-derived IL-25, but not Th17 cell-derived IL-17 or IL$17 \mathrm{~F}$, is crucial for murine asthma. J Immunol 2012; 189: 3641-52.

27. Song X, Qian Y. The activation and regulation of IL-17 receptor mediated signaling. Cytokine 2013; 62: 175-82.

28. Kang Z, Swaidani S, Yin W, et al. Epithelial cell-specific Act1 adaptor mediates interleukin-25-dependent hel- minth expulsion through expansion of Lin(-)c-Kit(+) in nate cell population. Immunity 2012; 36: 821-33.

29. Pan G, French D, Mao W, et al. Forced expression of murine IL-17E induces growth retardation, jaundice, a Th2-biased response, and multiorgan inflammation in mice. J Immunol 2001; 167: 6559-67.

30. Ballantyne SJ, Barlow JL, Jolin HE, et al. Blocking IL-25 prevents airway hyperresponsiveness in allergic asthma. J Allergy Clin Immunol 2007; 120: 1324-31.

31. Saenz SA, Taylor BC, Artis D. Welcome to the neighborhood: epithelial cell-derived cytokines license innate and adaptive immune responses at mucosal sites. Immunol Rev 2008; 226: 172-90.

32. Barron L, Wynn TA. Fibrosis is regulated by Th2 and Th17 responses and by dynamic interactions between fibroblasts and macrophages. Am J Physiol Gastrointest Liver Physiol 2011; 300: 723-8. 